\title{
Assessment of undergraduate students' tooth preparation for full veneer cast restorations
}

\author{
Nuha El-Mubarak ${ }^{1}$, Neamat Abu-Bakr ${ }^{1 *}$, Osama Omer², Yahia Ibrahim ${ }^{1}$ \\ ${ }^{1}$ Department of Oral Rehabilitation, Faculty of Dentistry, University of Khartoum, Khartoum, Sudan \\ ${ }^{2}$ Department of Restorative Dentistry and Periodontology, Dublin Dental School and Hospital, Dublin, Ireland \\ Email: neamat@yahoo.com, nhabubakr@uofk.edu
}

Received 10 November 2013; revised 15 December 2013; accepted 27 December 2013

Copyright (C) 2014 Nuha El-Mubarak et al. This is an open access article distributed under the Creative Commons Attribution License, which permits unrestricted use, distribution, and reproduction in any medium, provided the original work is properly cited. In accordance of the Creative Commons Attribution License all Copyrights (C) 2014 are reserved for SCIRP and the owner of the intellectual property Nuha El-Mubarak et al. All Copyright (C) 2014 are guarded by law and by SCIRP as a guardian.

\section{ABSTRACT}

Purpose: To evaluate tooth preparation for full veneer cast restorations performed by final year dental students in Sudan. Materials and Methods: 117 stone dies from two different dental institutions were collected and evaluated. Polyvinylsilioxane impression material was used to produce two impressive replicas of which one was sectioned in faciolingual plane and the other in mesiodistal plane. Occlusal clearance was measured using a digital caliper. Amount of axial preparation was also measured. Impression silhouettes that were produced using an overhead projector were used to measure convergence angle. Working casts were examined for smoothness and evenness of the preparations, existence or absence of additional features of retention and the finishing line were evaluated for its position and continuity. All obtained data were statistically analyzed by using T-test, ANOVA, and Pearson Chi square tests. P-values $\leq \mathbf{0 . 0 5}$ were considered as statistically significant. Results: Average taper of the examined preparations was $39.98^{\circ}$, with $44.1^{\circ}$ in the faciolingual, and $35.8^{\circ}$ in the mesiodistal dimensions. Preparations for full coverage restorations were over prepared. $38.5 \%$ of the total number of preparations were found to have finishing lines in the sub and supra gingival positions. $19.66 \%$ were unable to maintain continuity of the finishing line all around the preparation. All preparations were generally smooth with no sharp angles, and $1.7 \%$ of the preparations had additional retentive features. Conclusion: Within the limitations of this study, it could be concluded that the convergence angle and finishing line preparations were less than adequate in a sizeable proportion of the preparations

${ }^{*}$ Corresponding author. examined.

\section{KEYWORDS}

Fixed Prosthodontics; Tooth Preparation; Finish Lines; Impressions

\section{INTRODUCTION}

Proper tooth preparation is fundamental for accomplishing successful fixed partial denture work. Tooth preparation designs are governed by biological, mechanical and aesthetic principles. Strict clinical guidelines are emphasized in dental literature, but little information is available on how well these guidelines are followed [1]. The quality of preparation for extra coronal restorations is affected by occlusal reduction, axial reduction, taper, finishing line and undercuts in axial walls [2]. Goodacre et al. reviewed guidelines for scientific preparation and suggested nine scientific principles to guide the preparation [2]. It was suggested that $10^{\circ}-20^{\circ}$ as an ideal total occlusal convergence angle. The minimal occluso-cervical dimension for $10^{\circ}-20^{\circ}$ occlusal convergence is suggested to be $3 \mathrm{~mm}$ for incisors and premolars, and $4 \mathrm{~mm}$ for molars. Axial and occlusal reductions are $0.5 \mathrm{~mm}$ and $1 \mathrm{~mm}$ deep respectively for all metal, $1 \mathrm{~mm}$ and $2 \mathrm{~mm}$ respectively, for metal ceramic and all semi-translucent ceramic systems [2]. Despite strict clinical guidelines set for tooth preparation, laboratory technicians are still facing challenges in this respect. Error in tooth preparation was set as a second laboratory challenge directly after inadequate impression [3]. The continuation of the tooth preparation problems over a long time is astonishing, and the repetition of the same defects in spite of the records is questionable. It could be that these skills are difficult to learn or there is a lack of credit hours in teaching this 
subject, or maybe there is no proper communication between the dentist and laboratory technician. This problem has been the subject of several investigations which evaluated tooth preparation to see how much it is far from the ideal. These studies targeted preparations done by dental students [1,4-18], teaching staff [15], general practitioners $[7-9,15,19]$, residents $[4,20]$ and prosthodontists $[7,8,20]$, and different results have been reported. Most previous studies focused on one aspect of tooth preparations mainly taper [4-9,11,12,14-16,18,20,21], and few studies incorporated other aspects of tooth preparation in addition to taper $[1,13,17,22]$. Most of these studies were carried out in North America, Europe and Asia. Very little information is available concerning the ability of dentists in Africa to prepare teeth for full cast restorations [8]. There are many studies which followed the performance of dental students in tooth preparation for fixed prosthodontics during their pre-clinical course $[23,24]$ and efforts for accurate evaluation of their preclinical work were done [25,26].

The aim of this study is to evaluate the quality of tooth preparation for full veneer casting restorations performed by dental students in their final school year in Sudan.

\section{MATERIALS AND METHODS}

Two universities were selected for inclusion in this study. One was governmental and the other was private or nongovernmental. For the purpose of this study, approval was obtained from the two universities and the local research committee, but no special instructions that would differ from that for routine clinical procedures were given to either staff or students. The preparations were evaluated using casts and dies which were used only for the purpose of the present study. The samples from both institutions were considered as one sample and no attempts were made to merit or demerit preparations of either private or governmental institutions. Consent was obtained from the patients to include their dental casts in this study.

One hundred and seventeen working casts of the teeth prepared by final year dental students in the two dental schools were obtained. Each study cast and its working cast were marked by the same number, by using red marker for working cast and blue one for study cast.

For each preparation an impression was obtained. Impressions were made by using polyvinyl siloxane (Virtual/fast set/Ivoclar Vivadent AG, Schaan/Liechtenstein) loaded in perforated sectional trays. Polyvinyl siloxane putty material was loaded on the tray and adapted carefully over the appropriate site on the study cast. After setting, the putty impression was removed and trimmed carefully to fit precisely on the same location in the working cast. Light body (wash) impression material was then injected in the putty mould and an impression of the working cast was made.

To ensure proper seating of the study cast impressions on the working casts, red and green lines were made in certain anatomical landmarks i.e. labial and buccal fraenae of the study casts impressions and on the working casts. Proper seating of each impression on the working cast was ensured by the proper alignment of these two lines (Figure 1).

The impression making procedure was done twice for each study and working casts and then one silicone replica was sectioned faciolingually (FL) and the other mesiodistally (MD) in the mid axial plane (Figure 2).

Measurements for the taper were done by using a projector and transparent papers, projected images were produced. For each preparation, one sectioned replica was used to produce FL image and the other used to produce MD image. On the projected image two lines of opposing walls were drawn until they met together and the MD and FL convergence angles were then measured with a protractor.

The average taper equals: $\frac{\mathrm{FL}+\mathrm{MD}}{2}$

The anterior incisal reduction, occlusal reduction for

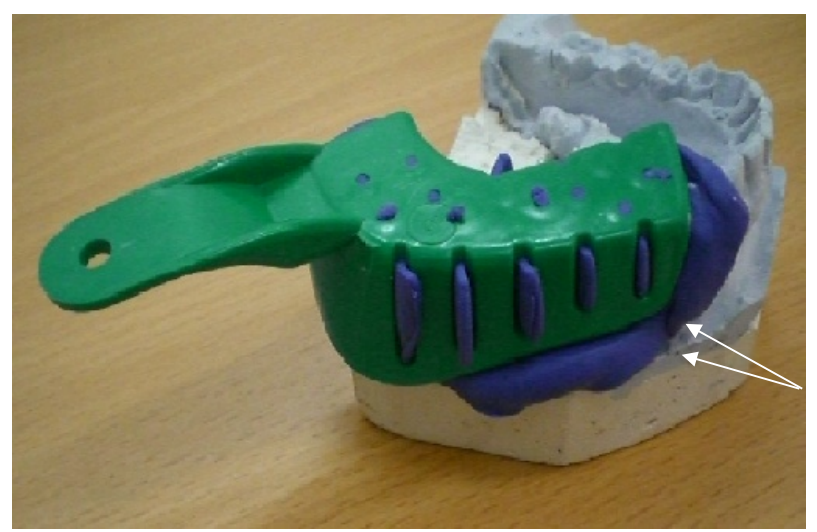

Figure 1. Seating of the study cast impression on the working cast (shown by the arrows).

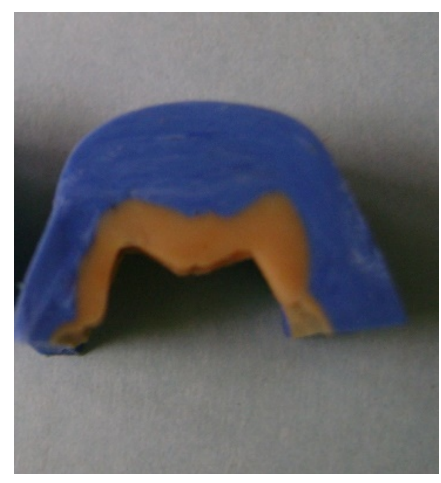

Figure 2. Silicone replica of a molar after sectioning. 
molar and premolar (working cusp, non-working cusp and central fossa) and axial reduction (buccal, lingual, mesial and distal) were measured directly on the impression replica by using a digital caliber. The working casts were also used to examine the finishing line continuity, position i.e. supra or subgingival and the smoothness and evenness of the preparations. A simple three point assessment scale of smoothness was used (good/moderate/ poor). The presence of additional retentive features was also noted i.e. if it was present or not. All these measurements were done by one investigator and randomly rechecked by another investigator. The evaluation criteria used for position of finishing line was that any finishing line placed more than $1 \mathrm{~mm}$ sub or supra-gingival was considered as too sub or supra-gingival. Severe mal-aligned teeth were excluded.

The collected data was entered into a computer via Epidata 3.1 and was sorted in a Data Master Sheet. Statistical package for social sciences (SPSS) version 15 (SPSS Inc., Chicago, USA) and STATA version 8 were used for data management (Stata Corp LP, Texas, TX, USA). T-test, one way analysis of variance (ANOVA), and Pearson Chi square tests were used to analyze the data. Confidence level of $95 \%$ was used, P-value less than 0.05 was considered as significant.

\section{RESULTS}

The present study investigated 17 teeth (14.5\%) that were prepared to construct crowns while the remaining 100 teeth (85.5\%) were prepared as abutments for fifty five FPD. All types of teeth were included in the study with approximating frequency. In teeth prepared for FPD, molars were the most frequently used abutments (29\%). While most of the teeth prepared for single crowns were premolars (52.94\%). Almost all the samples were prepared to receive full veneered restorations (Table 1). None of the prepared teeth were found to have an acceptable average taper as the clinically accepted range is $\left(10^{\circ}-20^{\circ}\right)$, while $8.5 \%$ of the prepared teeth had a clinically acceptable MD Taper and $(0.85 \%)$ had an acceptable buccolingually Taper (Table 2).

In this study BL taper was found to be higher than MD. Using t-test the result was found to be highly significant $(\mathrm{P}=0.0000)$. The average taper was significantly affected by the type of teeth i.e. whether it was anterior, canine, premolar or molar. Using one way analysis of variance (ANOVA), taper of canine preparations was found to be significantly higher than the other groups ( $P$ $=0.0001$ ) (Table 3).

By also using ANOVA, BL taper of canine teeth was found to be significantly higher than the other groups ( $P$ $=0.0000$ ), however, MD taper of canine and molars teeth were approximating each other and were higher than the other groups $(\mathrm{P}=0.0148)$ (Table 3$)$.
Table 1. Frequency of type of teeth included in the study, quality of the finishing line, smoothness of preparation and presence or absence of grooves.

\begin{tabular}{cc}
\hline Variable & Percentage \% (n) \\
\hline Aype of teeth included in the study & \\
Premolar & $23.08 \%(27)$ \\
Molar & $25.64 \%(30)$ \\
Canine & $29.06 \%(34)$ \\
Continuity of the finishing line & $22.22 \%(26)$ \\
Continuous & \\
Not continuous & $77.78 \%(91)$ \\
Not apparent & $19.66 \%(23)$ \\
Smoothness of the preparation & $2.56 \%(3)$ \\
Good & \\
Moderate & $70.09 \%(82)$ \\
Poor & $29.91 \%(35)$ \\
Presence ofgrooves & $0 \%(0)$ \\
Present & $100 \%(117)$ \\
Not present & $98.29 \%(115)$ \\
\hline
\end{tabular}

Table 2. The mean value for taper.

\begin{tabular}{cccc}
\hline Taper & Mean (SD) & In ideal range & Out of ideal \\
\hline Buccolingually taper & $44.1^{\circ}(11.2)$ & $0.85 \%(1)$ & $99.15 \%(116)$ \\
MD taper & $35.8^{\circ}(12.3)$ & $8.55 \%(10)$ & $91.45 \%(107)$ \\
Average taper & $39.98^{\circ}(9.6)$ & $0 \%(0)$ & $100 \%(100)$ \\
\hline
\end{tabular}

*Significant ( $\mathrm{P}=0.0000$ ) with $95 \%$ confidence interval.

Table 3. Tooth type versus taper of preparation.

\begin{tabular}{ccccc}
\hline Tooth type & $\begin{array}{c}\text { Percentage } \\
\%(\mathbf{n})\end{array}$ & $\begin{array}{c}\text { FL taper } \\
\text { Mean (SD) }\end{array}$ & $\begin{array}{c}\text { MD taper } \\
\text { Mean (SD) }\end{array}$ & $\begin{array}{c}\text { Average taper } \\
\text { Mean (SD) }\end{array}$ \\
\hline Incisors & $23.1 \%(27)$ & $41.6(7.1)$ & $30.3(12.5)$ & $35.9(7.6)$ \\
Canines & $22.2 \%(26)$ & $53.7(9)$ & $39.3(13.9)$ & $46.5(9.7)$ \\
Premolars & $25.6 \%(30)$ & $40.3(12.2)$ & $34.2(9.2)$ & $37.2(8.7)$ \\
Molars & $29.1 \%(34)$ & $42.3(10.8)$ & $38.96(11.7)$ & $40.6(9.2)$ \\
Total & $100 \%(117)$ & $44.1(11.2)$ & $35.8(12.3)$ & $39.98(9.2)$ \\
\hline
\end{tabular}

The mean of incisal reduction of anterior teeth was found to be $2.3 \mathrm{~mm}$ which was regarded as acceptable, however, when it was compared with the ideal using ttest the difference was statistically significant $(\mathrm{P}=$ 
$0.0020)$.

The mean occlusal the posterior teeth PFM was found to be $2.29 \mathrm{~mm}$ for functional cusp and $1.76 \mathrm{~mm}$ for nonfunctional cusp which was regarded as acceptable. Using t-test for comparison with the ideal, the result was found to be statistically significant with P-value 0.0004 and 0.0005 respectively. Central fossa reduction was found to be $1.6 \mathrm{~mm}$ (Table 4). For the amount of axial preparation; Facial reduction was $1.45 \mathrm{~mm}$ which was regarded clinically as ideal. The t-test revealed that the result was not statistically significant $(P=0.1490)$. Lingual reduction was found to be $1.00 \mathrm{~mm}$, mesial $1.42 \mathrm{~mm}$ and distal $1.37 \mathrm{~mm}$ which was regarded as clinically acceptable and by using t-test the results was found to be statistically significant $\mathrm{P}$-value $0.0000,0.0211$ and 0.0005 respectively (Table 4).

About $38.46 \%$ of students were unable to place the finishing line correctly; with the existence of subgingival and supra gingival lines at the same preparation. In 2.56\% of stone dies the finishing line was not clear. Sub and supragingival finishing lines were present in almost

Table 4. Amount of occlusal and axial clearance.

\begin{tabular}{cccc}
\hline $\begin{array}{c}\text { Occlusal preparation } \\
\text { in posterior teeth }\end{array}$ & $\begin{array}{c}\text { Percentage } \\
\text { (n) }\end{array}$ & Mean (SD) & $\begin{array}{c}\text { [95\% Conf. } \\
\text { Interval] }\end{array}$ \\
\hline Occlusal_FC (PFM) & $96.9 \%(62)$ & $2.29(0.61)$ & {$[2.13-2.45]$} \\
Occlusal_FC (M) & $3.1 \%(2)$ & $2.62(0)$ & {$[2.62-2.62]$} \\
Occlusal_NFC (PFM) & $96.9 \%(62)$ & $1.76(0.56)$ & {$[1.62-1.9]$} \\
Occlusal_NFC (M) & $3.1 \%(2)$ & $1.84(0.3)$ & {$[-0.83-4.51]$} \\
Occlusal_CF (PFM) & $96.9 \%(62)$ & $1.6(0.6)$ & {$[1.44-1.75]$} \\
Occlusal_CF (M) & $3.1 \%(2)$ & $1.8(0.04)$ & {$[1.48-2.11]$} \\
Axial preparation & & & \\
Facial & $\mathbf{1 0 0 \% ( 1 1 7 )}$ & & {$[1.38-1.52]$} \\
Facial (PFM) & $98.29 \%(115)$ & $1.45(0.39)$ & {$[1.28-1.44]$} \\
Facial (M) & $1.71 \%(2)$ & $1.33(0.4)$ & {$[-2.23-4.89]$} \\
Lingual & $\mathbf{1 0 0 \% ( 1 1 7 )}$ & & \\
Lingual (PFM) & $98.29 \%(115)$ & $1.01(0.3)$ & {$[0.95-1.06]$} \\
Lingual (M) & $1.71 \%(2)$ & $1.15(0.31)$ & {$[-1.65-3.95]$} \\
Mesial & $\mathbf{1 0 0 \% ( 1 1 7 )}$ & & \\
Mesial (PFM) & $98.29 \%(115)$ & $1.42(0.35)$ & {$[1.36-1.49]$} \\
Mesial (M) & $1.71 \%(2)$ & $1.3(0.59)$ & {$[-4.04-6.64]$} \\
Distal & $\mathbf{1 0 0 \% ( 1 1 7 )}$ & & \\
Distal (PFM) & $98.29 \%(115)$ & $1.36(0.43)$ & {$[0.15-1.3]$} \\
Distal (M) & $1.71 \%(2)$ & $0.73(0.06)$ & \\
\hline
\end{tabular}

(FC $=$ Functional cusp, NFC $=$ Non-functional cusp, $\mathrm{CF}=$ Central fossa, PFM = Porcelain fused to metal, $\mathrm{M}=$ Metal restoration). equal numbers. When continuity was assessed, most of students $(77.78 \%)$ were able to maintain continuity all around the preparation, although some of them (19.66\%) were unable to preserve continuity of the finishing line. Using Pearson chi square test to cross tabulate position of finishing line with continuity, it was found that most of discontinuous finishing lines were supra gingival and the difference was significant $(\mathrm{P}=0.000)$. All Preparations were smooth with no sharp angles. One hundred and fifteen (98.29\%) lacked the presence of extra retentive additional features while only two preparations (1.71\%) had proximal grooves (Table 1).

\section{DISCUSSION}

Tooth preparation is one of the main factors that influence the longevity of a restoration. The present study evaluated many aspects of tooth preparation. Greater care was taken in this investigation as detailed in the materials and method section to ensure proper seating of the study casts impression on the working casts in order to eliminate or minimize any seating inaccuracies.

The mean taper in this study was found to be $44.1^{\circ}$ faciolingually, $35.8^{\circ}$ mesiodistally with an average taper of $39.98^{\circ}$. These values were higher than what was recommended as acceptable in the literature $\left(4^{\circ}-14^{\circ}\right)[27,28]$, what was recommended by Goodacre et al who regarded $10^{\circ}-20^{\circ}$ as the acceptable clinical range [2], and were even higher than what was recorded from other studies which recruited dental students [1,4,6-11,13-18], teaching staff [13], general practitioner [7,13,17-19], residents $[4,20]$ and prosthodontists $[17,18]$. Other measurements for convergence angle reported were: $23.9^{\circ}$ by Al-Omari and Al-Wahadni [17], $25^{\circ}$ by Theophilus [17], $19^{\circ}$ by sato [15], $19.4^{\circ}$ by Annerstdet et al. [7], 19.1 ${ }^{\circ}$ by Noonan et al. [5], and $16.5^{\circ}$ by Mack [6]. Recent studies reported convergence angle values of: $19.2^{\circ}$ by Al Ali et al. [18] (20.3 $\mathrm{MD}, 18.3^{\circ}$ buccolingual $\{\mathrm{BL}\}$ ) by Rafeek et al. [14] in one study. In another study Rafeek et al. [16] reported a mean taper in anterior teeth of $31.6^{\circ} \mathrm{BL}$ and 16.8 $8^{\circ} \mathrm{MD}$ and $16.8^{\circ} \mathrm{BL}$ and $22.4^{\circ} \mathrm{MD}$ in the posterior teeth. Although many of these studies perform on dental students but the current result is obviously greater than taper measured by all previously mentioned studies, difference in measuring method may have some effect.

Although the students have the concepts of tooth preparation fresh in their mind it appears that the lack of clinical experience is the primary cause of the large taper in their preparations as most of preparations in the present study were their first clinical case, so getting large taper may not be surprising. In agreement with other studies $[5,7,10,11,17,18,20]$. the present study found that FL taper was greater than MD, which may be due to the convexity of buccal and lingual walls especially in the molar teeth which necessitate more preparation to avoid 
undercuts. However other studies found that MD was greater than FL $[1,13,14,21]$. Contrary to many other studies $[7,11,17,20,21]$ which reported molar teeth as having the highest taper, in the present study the canine teeth was found to have the highest taper which may be due to prominent cingulum that makes the preparation difficult for inexpert undergraduate students.

The present research included both crown and fixed partial denture preparations as one examined sample this will give a clear estimation or significant of any changes in preparation of a tooth as a single restoration or as an abutment for a fixed partial denture. In 1988, Nordlander et al. [20] examined both crown and fixed partial denture abutments as one examined sample. The present finding were in agreement with Nordlander et al. [20] where there was no significant difference in average taper of teeth prepared for crowns or for fixed partial dentures (FPD). Preparations for metallic restorations in the present study tend to be over prepared. Poons and Smales evaluated preparations for gold crowns and found that the preparations tend to be inadequate [1]. There are few studies to evaluate finishing line preparation either to evaluate width of the finishing line [1,11], angle between the finishing line and axial wall [1] and position of the finishing line using numerical values [22]. Only 1.71\% of the preparations in the present study were prepared with retentive grooves, these groove were added to abutment teeth of fixed partial denture; despite of large taper in most of the preparations, this might be due to inexperience which resulted in failure to see the need for extra retentive features in such situations. In general students have no problems in getting smooth preparations with rounded angles. Slight errors in visual estimation, minimal experience of students and the fact that the students in both institutions start their clinical requirements in fixed prosthodontics after a relatively long period of completion of their laboratory course might be the causes of less than ideal preparations. In addition, possibly the length and content of the preclinical course in both institutions might have an impact on the clinical performance of the students. Training in clinical or preclinical courses without utilizing proper teaching aids [29-31] or support systems [32] could have a negative impact on the operative performance of the students.

\section{CONCLUSION}

Within the limitation of this study, it could be concluded that the taper achieved by the dental students was more than that was recommended in the dental literature. There were no additional features to improve retention in spite of the increase in taper. Occlusal and axial preparations were regarded as acceptable when compared with the ideal. Most of the preparations had smooth and continuous finishing lines, although discontinuity was not uncommon. In general, preparations were smooth with no irregularities or sharp angles. The main recommendations of this study were to increase the duration of the preclinical course, and more emphasis should be placed on the clinical practice of tooth preparation. Long-term clinical studies are necessary to fully assess the longevity of full veneered restorations to see the influence of less than ideal taper on the success of these restorations.

\section{REFERENCES}

[1] Poon, B.K. and Smales, R.J. (2001) Assessment of clinical preparations for single gold and ceramometal crowns. Quintessence International, 32, 603-610.

[2] Goodacre, C.J., Campagni, W.V. and Aquilino, S.A. (2001) Tooth preparations for complete crowns: An art form based on scientific principles. The Journal of Prosthetic Dentistry, 85, 363-376.

http://dx.doi.org/10.1067/mpr.2001.114685

[3] Christensen, G.J. (2007) Frequently encountered errors in tooth preparations for crowns. Journal of the American Dental Association, 138, 1373-1375. http://dx.doi.org/10.14219/jada.archive.2007.0055

[4] Dorriz, H., Nokar, S., Baghai Naini, R. and Madadi, A. (2008) The convergence angle of full-coverage crown preparations made by dental students. Journal of Dentistry of Tehran University of Medical Sciences, 5, 37-41.

[5] Noonan Jr., J.E. and Goldfogel, M.H. (1991) Convergence of the axial walls of full veneer crown preparations in a dental school environment. Journal of Prosthetic Dentistry, 66, 706-708. http://dx.doi.org/10.1016/0022-3913(91)90457-8

[6] Mack, P.J. (1980) A theoretical and clinical investigation into the taper achieved on crown and inlay preparations. Journal of Oral Rehabilitation, 7, 255-265. http://dx.doi.org/10.1111/j.1365-2842.1980.tb00443.x

[7] Al-Ali, K., Al-Wazzan, K., Al-Amri, M., Al-Shahrani, A., Al-Shahrani, M. and Al-Qahtani, H. (2009) Assessment of convergence angle of full veneer preparations carried out by practitioners with different levels of experience. Saudi Dental Journal, 21, 37-44.

[8] Theophilus, C.E. (2004) The taper of clinical crown preparations done by dental students and dentists in two African countries: A comparative analysis. M.Sc. Thesis, University of the Western Cape, South Africa.

[9] Annerstedt, A., Engstrom, U., Hansson, A., Jansson, T., Karlsson, S., Liljhagen, H., et al. (1996) Axial wall convergence of full veneer crown preparations. Documented for dental students and general practitioners. Acta Odontologica Scandinavica, 54, 109-112. http://dx.doi.org/10.3109/00016359609006014

[10] Smith, C.T., Gary, J.J., Conkin, J.E. and Franks, H.L. (1999) Effective taper criterion for the full veneer crown preparation in preclinical prosthodontics. Journal of Prosthodontics, 8, 196-200. http://dx.doi.org/10.1111/j.1532-849X.1999.tb00035.x

[11] Ayad, M.F., Maghrabi, A.A. and Rosenstiel, S.F. (2005) 
Assessment of convergence angles of tooth preparations for complete crowns among dental students. Journal of Dentistry, 33, 633-638.

http://dx.doi.org/10.1016/j.jdent.2004.12.008

[12] Ohm, E. and Silness, J. (1978) The convergence angle in teeth prepared for artificial crowns. Journal of Oral Rehabilitation, 5, 371-375. http://dx.doi.org/10.1111/j.1365-2842.1978.tb01256.x

[13] Al-Omari, W.M. and Al-Wahadni, A.M. (2004) Convergence angle, occlusal reduction, and finish line depth of full-crown preparations made by dental students. Quintessence International, 35, 287-293.

[14] Okuyama, Y., Kasahara, S. and Kimura, K. (2005) Quantitative evaluation of axial wall taper in prepared artificial teeth. Journal of Oral Science, 47, 129-133. http://dx.doi.org/10.2334/josnusd.47.129

[15] Patel, P.B., Wildgoose, D.G. and Winstanley, R.B. (2005) Comparison of convergence angles achieved in posterior teeth prepared for full veneer crowns. European Journal of Prosthodontics and Restorative Dentistry, 13, 100-104.

[16] Rafeek, R.N., Marchan, S.M., Seymour, K.G., Zou, L.F. and Samarawickrama, D.Y. (2006) Abutment taper of full cast crown preparations by dental students in the UWI School of Dentistry. European Journal of Prosthodontics and Restorative Dentistry, 14, 63-66.

[17] Sato, T., Al Mutawa, N., Okada, D. and Hasegawa, S. (1998) A clinical study on abutment taper and height of full cast crown preparations. Journal of Medical and Dental Sciences, 45, 205-210.

[18] Rafeek, R.N., Smith, W.A., Seymour, K.G., Zou, L.F. and Samarawickrama, D.Y. (2010) Taper of full-veneer crown preparations by dental students at the University of the West Indies. Journal of Prosthodontics, 19, 580-585. http://dx.doi.org/10.1111/j.1532-849X.2010.00625.x

[19] Kissov, H.K. and Chalashkanova, M.I. (2001) The impression as a means for analysis of clinical mistakes in fixed prosthodontics. Folia Medica (Plovdiv), 43, 84-87.

[20] Nordlander, J., Weir, D., Stoffer, W. and Ochi, S. (1988) The taper of clinical preparations for fixed prosthodontics. Journal of Prosthetic Dentistry, 60, 148-151. http://dx.doi.org/10.1016/0022-3913(88)90304-6

[21] Kent, W.A., Shillingburg Jr., H.T. and Duncanson Jr., M.G. (1988) Taper of clinical preparations for cast restorations. Quintessence International, 19, 339-345.

[22] Motofumi, S., Yoshinobu, M., Kaoru, K. and Hideki, Y. (2005) Method of objectively evaluating tooth preparation during clinical training. Prosthodontic Research \&
Practice, 4, 98-102. http://dx.doi.org/10.2186/prp.4.98

[23] Ingebrigtsen, J., Roynstrand, E. and Berge, M.E. (2008) An evaluation of the preclinical prosthodontic training at the Faculty of Dentistry, University of Bergen, Norway. European Journal of Dental Education, 12, 80-84. http://dx.doi.org/10.1111/j.1600-0579.2007.00489.x

[24] Clancy, J.M., Lindquist, T.J., Palik, J.F. and Johnson, L.A. (2002) A comparison of student performance in a simulation clinic and a traditional laboratory environment: Three-year results. Journal of Dental Education, 66, 1331-1337.

[25] Esser, C., Kerschbaum, T., Winkelmann, V., Krage, T. and Faber, F.J. (2006) A comparison of the visual and technical assessment of preparations made by dental students. European Journal of Dental Education, 10, 157161. http://dx.doi.org/10.1111/j.1600-0579.2006.00408.x

[26] Cardoso, J.A., Barbosa, C., Fernandes, S., Silva, C.L. and Pinho, A. (2006) Reducing subjectivity in the evaluation of pre-clinical dental preparations for fixed prosthodontics using the Kavo Prep Assistant. European Journal of Dental Education, 10, 149-156. http://dx.doi.org/10.1111/j.1600-0579.2006.00409.x

[27] Shillingburg, H.T., Hobo, S., Whitsett, L.D., Jacobi, R. and Brackett, S.E. (1997) Fundamentals of fixed prosthodontics. 3rd Edition, Quintessence Publishing, Chicago, 120-121.

[28] Rosenstiel, S.F., Land, M.F. and Fujimoto, J. (2001) Contemporary fixed prosthodontics. 3rd Edition, Mosby Inc., St Louis, 183-184.

[29] Parker, M.H., Ivanhoe, J.R., Blalock, J.S., Frazier, K.B. and Plummer, K.D. (2003) A technique to determine a desired preparation axial inclination. The Journal of Prosthetic Dentistry, 90, 401-405. http://dx.doi.org/10.1016/S0022-3913(03)00516-X

[30] Kaplowitz, G.J. (2002) An aid to proximal wall reduction for full crowns. Journal of the American Dental Association, 133, 72.

http://dx.doi.org/10.14219/jada.archive.2002.0024

[31] Kawagoe, Y. (1990) A study on tooth preparation by means of the newly developed parallelometer and its educational effect, with primary regard to convergence angles of abutment tooth. Kanagawa Shigaku, 25, 292305.

[32] Nishida, M., Sohmura, T. and Takahashi, J. (2004) Training in tooth preparation utilizing a support system. Journal of Oral Rehabilitation, 31, 149-154. http://dx.doi.org/10.1046/j.0305-182X.2003.01216.x 